\title{
Temperature-controlled light-emitting diode lamp for photovoltaic rural applications
}

\author{
Alfonso Gago-Calderón ， José Fernández-Ramos and Luis Narvarte
}

\begin{abstract}
In recent years, interest in light-emitting diode (LED) lighting has been growing because of its high efficacy, lifetime and ruggedness. This paper proposes a better adaptation of LED lamps to the technical requirements of photovoltaic lighting domestic systems, whose main quality criteria are reliability and that behave as voltage power supplies. As the key element of reliability in LED lamps is temperature, a solution is proposed for driving LED lamps using voltage sources, such as photovoltaic system batteries, with a control architecture based on pulse width modulation signal that regulates the current applied according to the LED lamp temperature. A prototype of the LED lamp has been implemented and tested to show its good performance at different temperatures and at different battery voltages.
\end{abstract}

KEYWORDS

PV rural applications; LED lighting; temperature control

\section{INTRODUCTION}

Within only a few years, light-emitting diode (LED) lighting has gone from being a promising technology [1] to becoming a real alternative in general lighting. The objective of this paper is to improve the adaptation of LED lighting technology to photovoltaic (PV) lighting domestic systems.

There are many inherent advantages of LEDs over conventional types of lighting systems such as higher efficacy, increased lifetime (measured in tens of thousands of hours), ruggedness, environmental friendliness (no mercury or lead), compact size and low operating voltages [2], which make them suitable for PV applications. The efficacy of current phosphor-converted LEDs has exceeded $100 \mathrm{~lm} / \mathrm{W}$ [3]. This value of LED efficacy makes this sort of lamp very competitive when comparing them with other light sources used in PV-powered lighting systems [4].

The main quality criterion for PV decentralized applications is reliability. In previous works [5], several technical specifications and testing procedures have been developed to evaluate the quality of lamps for solar home systems: lamp reliability under normal, extreme and abnormal operation conditions and lamp luminosity. From this point of view, the main characteristic of LED lamps that has to be reviewed is their reliability and, consequently, their lifetime. The lifetime of conventional light sources for PV applications is set as the number of on/off cycles that they support until they stop producing light. In the case of LED lamps, this means avoiding catastrophic failures (that rarely occurs in properly biased LEDs but in the associated electronic components) and retarding light output degradation over time. There are two industry end-of-life metrics in terms of light degradation. One is the L70 or life to $70 \%$ of original emission, and the other is L50 point or $50 \%$ emission point. Typically the L70 point is used as the useful life of a LED lamp [3]. Narendran et al. [6] found that the light output decreases in an exponential manner as the temperature operation of LED increases. Figure 1 shows this relationship for a commercial LED. We can see that, for the nominal current of $350 \mathrm{~mA}$, the lifetime can be increased by $25 \%$ if the junction temperature is reduced from $80^{\circ} \mathrm{C}$ to $65^{\circ} \mathrm{C}$. Furthermore, the reliability of the electronic components used for the LED drivers is also highly dependent on temperature. Therefore, we can conclude that the thermal management is the key aspect to guarantee the reliability of LED lamps in PV applications. In fact, 


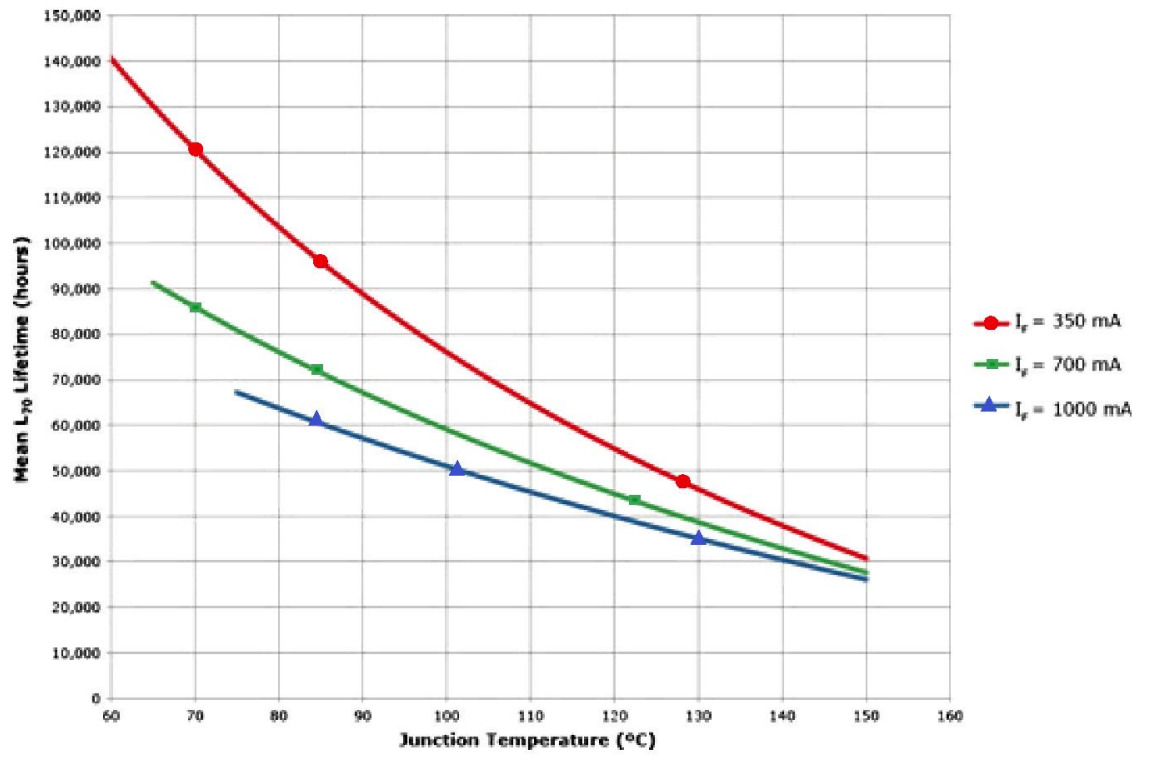

Figure 1. Lifetime $(L 70)$ estimation of the MX-6 white light-emitting diode by Cree $\left(T_{\text {air }}=45^{\circ} \mathrm{C}\right)$.

the main problem found on installations with LED lamps related to PV rural electrification programs is the management of the heat generated inside the lamp projectors, especially in outdoor, high power applications.

Current LED lamps are based on constant current (IDC) sources to drive the LEDs, which do not suit PV systems very well due to the following reasons:

i IDC sources reduce the reliability of LED lamps because they do not control the temperature in the diodes and include components that are not as reliable as the LEDs, which are usually the weakest points of these types of lamps.

ii Stand-alone PV systems keep the generated energy in batteries. These storage equipment behave as a constant voltage (VDC) power supply, so, in order to connect a constant current LED lamp, it is necessary to use a DC-DC converter that provides a currentregulated output. They, overall, reduce efficiency, performance and, as mentioned, reliability.

In this paper, we propose a new LED lamp without IDC sources or DC-DC converters. It can be directly connected to the PV system batteries and implies the employment of one unique LED driver based on an intelligent digital controller that uses the LED temperature as feedback information. In this way, its reliability and efficacy are increased, making this LED lamp suitable for stand-alone applications.

The main characteristics of this new driver are the following:

- The control variable is the temperature of the LEDs instead of their applied voltage or the forward current.

- The power regulation is based on pulse width modulation (PWM) that is performed by a microcontroller.
- The lamp is directly connected to the PV system batteries, through the charge regulator, without the need for a power supply or DC-DC converter.

- Special features, useful in stand-alone PV systems, such as a timed automatic shutdown or an efficient dimming of light, can also be performed by the microcontroller.

\section{OPTIMAL LIGHT-EMITTING DIODE DRIVING TECHNIOUES FOR PHOTOVOLTAIC APPLICATIONS}

The illuminance of a power LED depends basically on two factors: the forward current and its junction temperature. Given a constant junction temperature, the illuminance varies linearly with the forward current at small currents and tends to saturate at high current values [7]. However, if a constant current status is forced, the illuminance falls while the temperature increases. The $I-V$ curve of the LED is exponential, and the relationship between the applied voltage and the LED junction temperature is approximately proportional (typically $-3.3 \mathrm{mV} /{ }^{\circ} \mathrm{C}$ ). At a given constant luminance, the power consumption increases with temperature. Figure 2(a-d) shows, as an example, these relationships for the MX-6 model by Cree manufacturer (Durham, NC, USA) [8].

Therefore, if a constant forward current is applied to the LED, the increase in the junction temperature only causes a slight decrease in its voltage drop and in the illumination obtained, creating a natural mechanism of negative feedback. However, if a constant direct voltage is applied to the LED, the same increase in temperature would produce an exponential increase of the forward current and finally a catastrophic failure of the device. This is the reason why IDC sources are used as the standard method of driving LEDs [9]. 
(a)

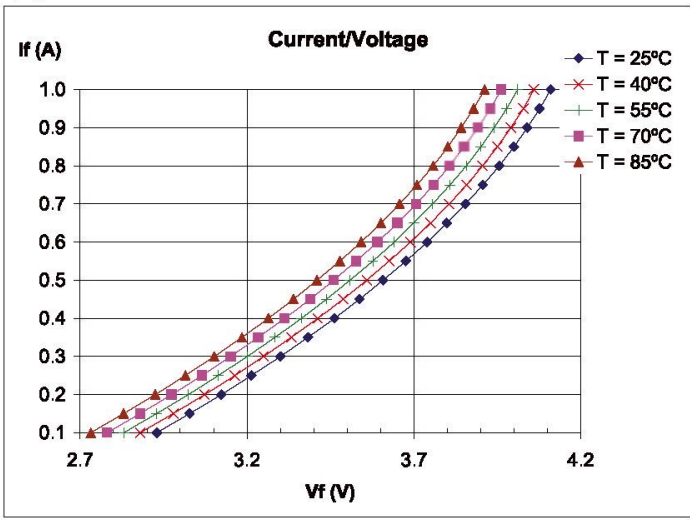

(c)

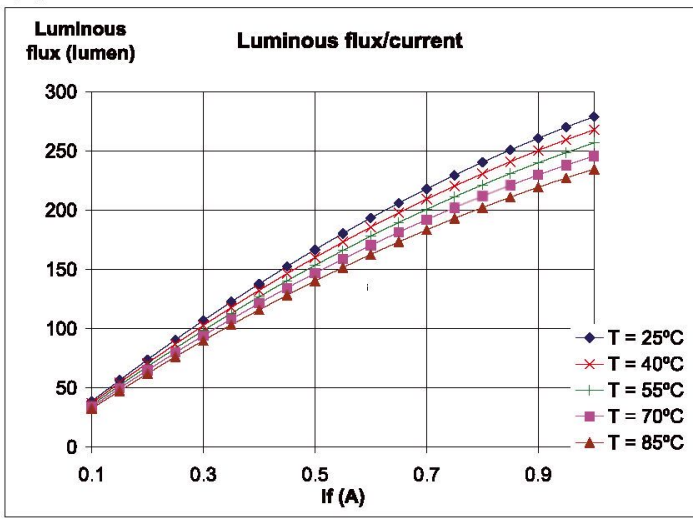

(b)

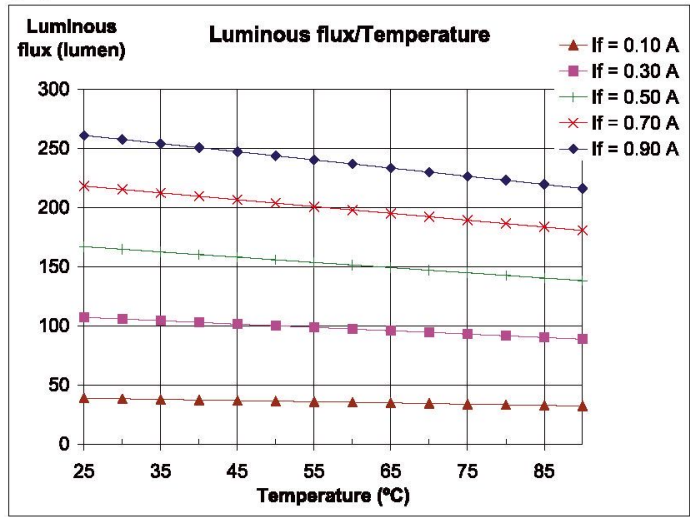

(d)

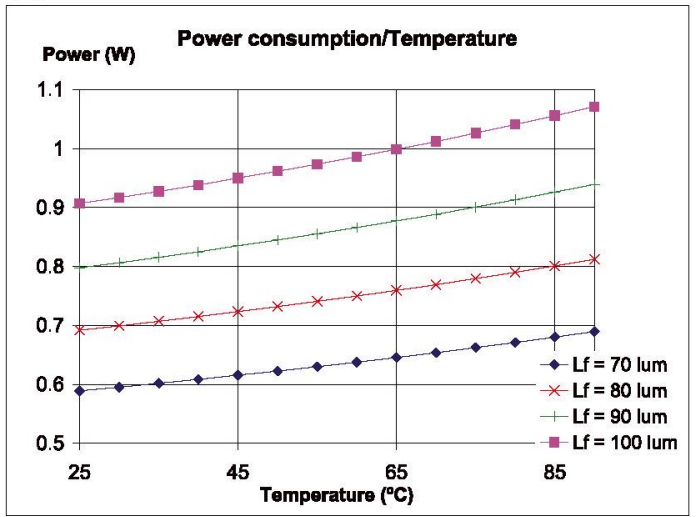

Figure 2. (a-d) Working parameters of the $M X-6$ white light-emitting diode by Cree.

However, the usage of these kinds of power supplies on PV autonomous systems has two main drawbacks. As explained, they avoid a fatal breakdown of the lamp but they do not have any possibility to avoid uncontrolled increases of the LED junction temperature, as this depends not only on the current driving but also on the ambient temperature and the heat dissipation capability of the dissipater where the LEDs are placed. Because of this, it is very difficult to control and protect the lifetime of the LEDs, especially when ambient temperature is high, which is quite common in the places where these systems are placed.

Batteries of PV stand-alone systems behave as a constant voltage power supply. A constant current output needs extra equipment with the consequent increment of cost and loss of efficiency and reliability. Consequently, the optimal LED driving technique would be that which eliminates IDC sources and directly uses the PV system battery as a voltage source for driving the LEDs but, somehow, avoids the risk of excessive temperature.

\subsection{Pulse width modulation regulation based on temperature control}

Taking into account the capacity of the LEDs to regulate their luminosity with high efficiency [10], we propose a technology for driving LED lamps using voltage sources, such as PV system batteries, with a control architecture based on a PWM signal that regulates the input current using the LED temperature as its criteria. The basic working principle is to assure that the temperature inside the light-emitting semiconductor is always kept in the range that guarantees a maximum lifetime of the lamp, regardless of ambient conditions. The control architecture regulates the width of the active pulse of the PWM signal to adapt the power consumption of the LEDs to their thermal condition. In this way, when the working temperature overpasses the level that guarantees the expected lifetime, the duty-cycle of the PWM is reduced. This implies reducing the heat generation as well as the global brightness level of the lamp. This situation can be caused either by abnormal working operation conditions, such as reduced radiation capability by dust or other external obstacles or by unusually high ambient temperatures. For this reason, a good design of the lamp heat radiator will guarantee that the working temperature of the LEDs will be within the required range for the external ambient conditions it has been prepared for.

The power input duty-cycle signal is established by a microcontroller, using the information obtained by a temperature sensor placed inside the LED matrix and in contact with the heat dissipation surface of the LEDs' printed 
circuit board. Thus, the active period of the LED driving signal will depend on the readings of this sensor. A mechanism of negative feedback compensates the increase of current produced by the increments of temperature inside the LEDs that are powered with constant voltage.

A power metal oxide semiconductor field-effect transistor (MOSFET) is all that is necessary as an interface to connect the LED matrix with the battery voltage. Its function is to plug or unplug the anode of the lighting diodes from the power supply depending on the exact status of the PWM control signal. The switching commutation frequency must be high enough to avoid any flickering of the light that could be perceived by the human eye. Figure 3 shows the proposed schematic design of the lamp control architecture.

The main characteristics of this control architecture are the following

- It requires very little extra hardware:

- one general purpose low-power microcontroller,

- one temperature sensor

- and one power MOSFET.

All these devices are robust and low cost, and they present no problem working under hard ambient conditions with very high reliability.

- No complex electronic circuit is necessary to provide a constant current flow. In this way, it is possible to avoid the usage of a large number of resistors, inductors or electrolytic capacitors that reduces the efficiency and reliability of the lighting equipment.

- It offers a precise way to control the polarization level of the LEDs as it is possible to control the frequency and the duty-cycle of the PWM power supply signal easily and exactly. This implies an efficient and smooth brightness control using the information of the temperature on the LED matrix that shows no flickering or rough changes.

- It can be used with a power supply based on a non-stabilized constant voltage system.

\section{PRACTICAL IMPLEMENTATION AND EVALUATION}

\subsection{Practical implementation}

In order to evaluate the benefits of this proposal, a test LED lamp prototype has been set up. This equipment can be powered by using an adjustable IDC source connected directly to the LED matrix or by the proposed control architecture connected to an adjustable VDC voltage power supply. In this latter case, the microcontroller has been programmed to keep a constant working temperature. The purpose of this test is to compare the behavior of the lamp under these two different control paradigms. A switch placed on the LED matrix allows changing from one control to the other. Figure 4 shows the scheme of the bench test.

The algorithm for temperature control in this case is simple. It is based on fixing a target temperature that is the desired constant value for the LED matrix. This value can be configured depending on the ambient temperature of the place and the physical installation of the lamp. It must be adequate to the expected lifetime desired and the illuminance values that must be achieved. The microcontroller does a proportional-integral control routine based on the difference between the temperature measured and the desired one and implemented by the duty-cycle of the PWM signal that controls the power supply of the LED matrix. The frequency of the PWM signal has been

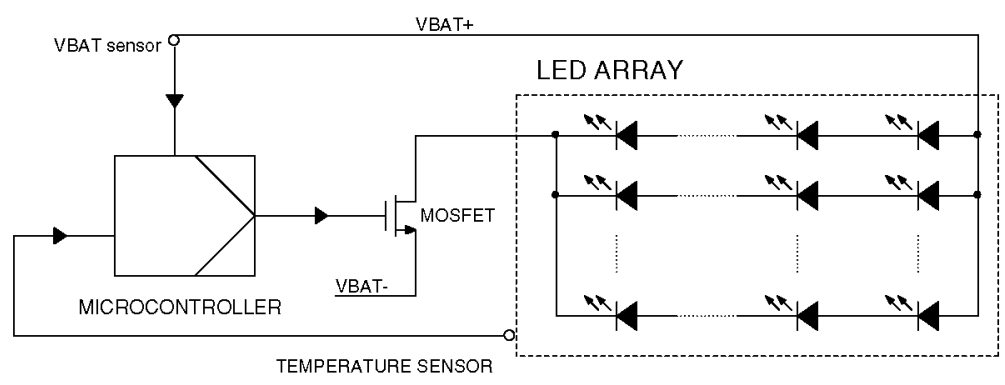

Figure 3. Digital light-emitting diode (LED) lamp constant voltage control system with temperature feedback schematic. MOSFET, metal-oxide semiconductor field-effect transistor; VBAT, battery voltage.

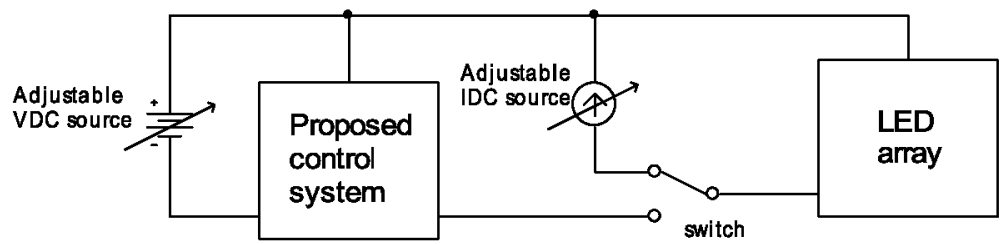

Figure 4. Scheme of the bench test. LED, light-emitting diode. 
established on $5 \mathrm{kHz}$. This value is high enough to avoid any flickering on the emitted light and low enough to neglect the switching losses in the MOSFET.

Figure 5 shows the LED matrix of the lamp prototype It contains 16 LEDs manufactured by Cree (model MX-6, intensity bin Q4). The LED matrix has four strings of four LEDs each. The heat aluminum radiator has been designed to work at an ambient temperature of $40^{\circ} \mathrm{C}$ at a duty-cycle of $100 \%$ (nominal conditions), whereas the LEDs are always at around $70^{\circ} \mathrm{C}$. This temperature ensures a lifetime expectation of over $120000 \mathrm{~h}$ [8]. Working under these conditions, this LED model has a light conversion efficiency of approximately $100 \mathrm{~lm} / \mathrm{W}$. With this value, the test lamp prototype must have around $1200 \mathrm{~lm}$ for a nominal input power of $12 \mathrm{~W}$.

The inside chip LED temperature has been estimated to be between $3^{\circ} \mathrm{C}$ and $7^{\circ} \mathrm{C}$ above the temperature measured on the digital sensor placed on the printed circuit board where the LEDs are soldered. For this reason, the target temperature of the microcontroller firmware has been established at $65^{\circ} \mathrm{C}$, which leads to a junction temperature between $68^{\circ} \mathrm{C}$ to $72^{\circ} \mathrm{C}$ on every working situation for which it has been designed.

As Figure 5 shows, the LED matrix includes a p-channel MOSFET in series with a resistor ( $R$ ). This circuit is in parallel with the four LEDs connected to the positive terminal of the battery. This scheme is designed to take into account that stand-alone PV systems have a wide range of voltage supply. For a system of $12 \mathrm{~V}$ nominal voltage, the voltage supply can range between 11 and $15 \mathrm{~V}$. The exponential $I-V$ relationship of a white LED takes the effect that the brightness decreases dramatically when the voltage is less than $12 \mathrm{~V}$ ( $3 \mathrm{~V}$ per diode), making the luminance unsatisfactory. In the proposed LED matrix structure, p-channel MOSFET (MP) is off in normal operation. The microcontroller sets MP when it detects that the voltage supply is less than a previously programmed threshold voltage. In this case, $\mathrm{R}$ is in parallel with the first four LEDs. The $\mathrm{R}$ is chosen so that all the current flows through it and the four LEDs do not stay on. Therefore, the voltage at these LEDs is reduced, and the voltage at the rest of the LEDs and its brightness are increased.

The value of $\mathrm{R}$ in the lamp prototype is $2.7 \Omega$. It has been calculated so that when MP is set, the brightness of each one of the 12 LEDs that are on is the same as the brightness of each LED under nominal lamp conditions. In this way, when MP switches on, the brightness of the lamp will be $75 \%$ of the nominal. To avoid a sudden change in brightness, the programmed threshold voltage should be selected so that the MP switching that occurs for a voltage supply that makes the lamp's brightness is $75 \%$ of its nominal value. In this way, it has been set at $12.2 \mathrm{~V}$.

Figure 6 shows different details of the prototype. It should be noted that this design allows the lamp to be used in the standard sockets of fluorescent lamps.

\subsection{Evaluation}

The performance of the prototype under the two alternative testing control conditions has been measured inside an opaque-isolated camera with temperature control. To measure the illuminance, we have installed inside this chamber a Jung WS10H model brightness sensor (Albrecht Jung $\mathrm{GmbH} \& \mathrm{Co}$. KG, Schalksmühle, Germany). It was placed at $134 \mathrm{~cm}$ from the middle of the lamp.

We have controlled, besides the ambient camera temperature, the value of this parameter on the outer surface of the heat radiator of the lamp using a standard Pt100 probe connected to a Baumer 2201 temperature transmitter (Baumer Holding AG, Frauenfeld, Switzerland) configured on the temperature range of $-10^{\circ} \mathrm{C}$ to $110^{\circ} \mathrm{C}$.

A first set of measurements of the lamp performance has been made using a constant voltage input of $12.55 \mathrm{~V}$. We have prepared the test camera to be at a constant ambient temperature of $40^{\circ} \mathrm{C}$ (lamp nominal). Once this temperature has been reached and stabilized, the lamp has been powered with the desired value and has been kept turned on until it reached a stationary status where the radiator temperature stays constant. At

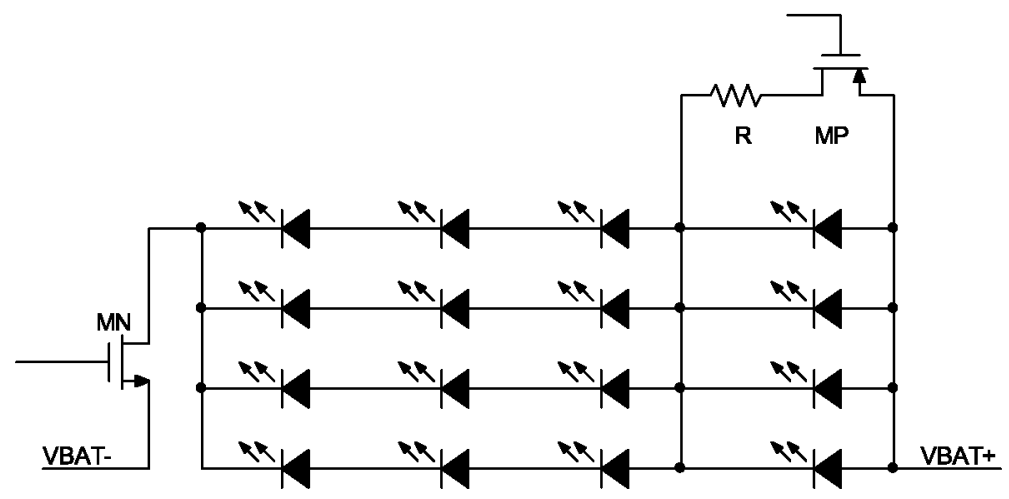

Figure 5. Light-emitting diode matrix diagram of the lamp prototype. VBAT, battery voltage; R, resistor; MN, n-channel MOSFET; MP, p-channel MOSFET. 


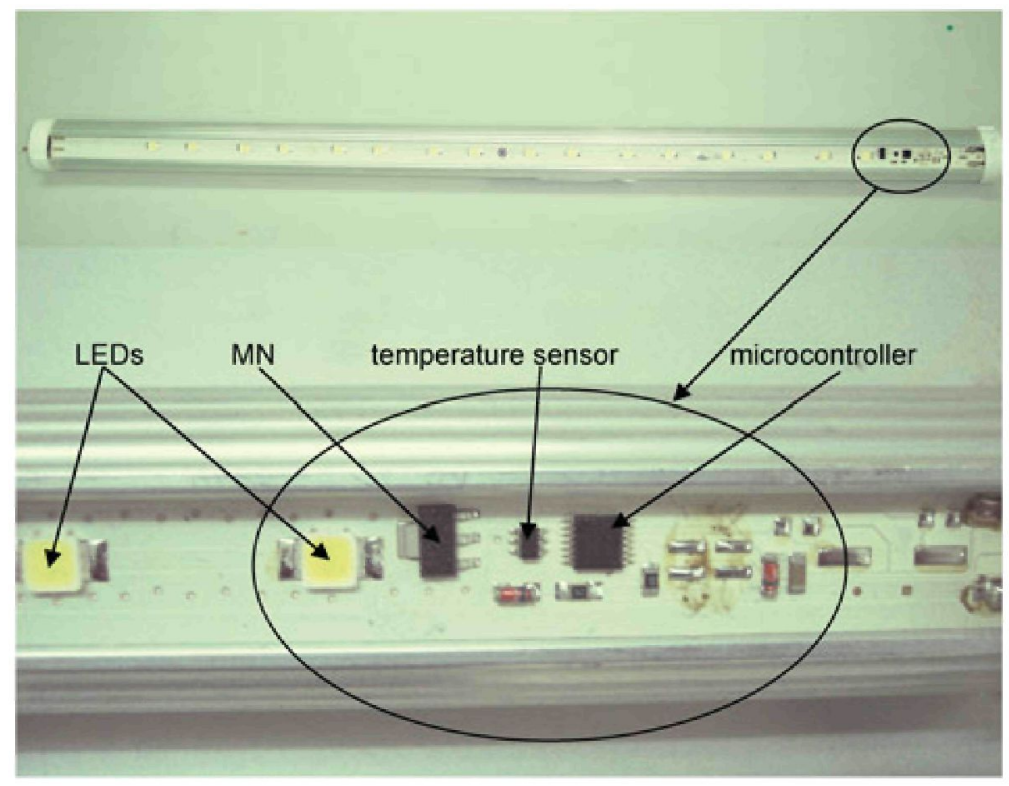

Figure 6. Global and detailed view of the lamp. LEDs, light-emitting diodes; MN.

that moment, the illuminance, current consumption, duty-cycle of the PWM signal and the temperature on the lamp were measured. These values will be considered as the nominal working conditions for our test lamp. The luminance at these conditions has been estimated using the data provided by manufacturer. The relationship between luminance and illuminance has been used for the calculation of the luminance in the remaining tests performed.

Finally, the ambient temperature of the test cabin has been established to two different extreme test values: $16^{\circ} \mathrm{C}$ and $50^{\circ} \mathrm{C}$, and the lamp prototype has been tested again on the same basis with the two alternative working methods under comparison: constant current and constant voltage with temperature feedback control. Complete test results are shown in Table I.
The conclusions obtained from the previous results are at high ambient temperatures $\left(50^{\circ} \mathrm{C}\right)$, the control system based on controlling the lamp temperature acts with high efficiency, maintaining the working temperature close to the target value in our design. However, when using the constant current control technique, the temperature measured on the LED matrix is about $80^{\circ} \mathrm{C}$, which means that the temperature on the chip of the light diodes is at least $85^{\circ} \mathrm{C}$. At this temperature, the estimated lifetime of the LEDs decreases by $25 \%$. Another important advantage of the new controlling constant voltage PWM technique is that the energy efficiency of the LED lamp is improved by about $23 \%$ compared with the constant current test measurements under the same ambient conditions. The only drawback is that, when the lamp enters into the regulation process at high ambient temperature $\left(\approx 50^{\circ} \mathrm{C}\right)$, the

Table I. Comparison between the two operating modes.

\begin{tabular}{lccccc}
\hline & $\begin{array}{c}\text { Nominal } \\
\text { values }\end{array}$ & $\begin{array}{c}\text { Temperature regulation } \\
\text { mode }\end{array}$ & $\begin{array}{c}\text { Constant current } \\
\text { mode }\end{array}$ & $\begin{array}{c}\text { Temperature regulation } \\
\text { mode }\end{array}$ & $\begin{array}{c}\text { Constant current } \\
\text { mode }\end{array}$ \\
\hline Room temperature $\left({ }^{\circ} \mathrm{C}\right)$ & 40 & 50 & 50 & 16 & 16 \\
Lamp temperature $\left({ }^{\circ} \mathrm{C}\right)$ & 59.0 & 65.1 & 78.9 & 25.3 & 28.4 \\
Lamp voltage (V) & 12.55 & 12.55 & 12.31 & 12.55 & 12.92 \\
Lamp current (A) & 0.98 & 0.42 & 0.98 & 0.80 & 0.98 \\
Lamp power (W) & 12.30 & 5.27 & $12.70^{*}$ & 10.04 & $13.33^{*}$ \\
Illuminance (Ix) & 145 & 72 & 139 & 129 & 148 \\
Luminance (Im) & 1230 & 610 & 1174 & 1093 & 1255 \\
Luminance/nominal & 100.00 & 49.59 & 95.45 & 88.84 & 102.07 \\
luminance (\%) & & & & 100.00 & 108.84 \\
Duty-cycle (\%) & 100.00 & 50.13 & 92.46 & 108.83 & 94.19 \\
Efficacy (Im/W) & 100.01 & 115.71 & 92.45 & & 94.19 \\
Efficacy/nominal & 100.00 & 115.70 & & & \\
efficacy $(\%)$ & & & & & \\
\hline
\end{tabular}

*Power consumption has been calculated considering a constant voltage-constant current conversion efficiency of $95 \%$. 
luminance obtained is reduced to $52 \%$ compared with a non-regulated status with a constant current control technique. However, the luminance level $(610 \mathrm{~lm})$ and the lamp efficacy $(115.7 \mathrm{~lm} / \mathrm{W})$ remain high enough.

On the other hand, when considering the results obtained with low ambient temperature $\left(16^{\circ} \mathrm{C}\right)$, the temperature feedback architecture still keeps an efficiency higher than $15 \%$ from the one obtained with constant current. In this case, the brightness is below the nominal design value $(88.8 \%$ ) because of the smaller amount of current that can be driven via the LEDs under the same voltage input value at lower temperatures and, in the same way, the brightness. Nevertheless, luminance levels are still high $(1093 \mathrm{~lm})$, whereas the power consumption levels decrease significantly $(18.4 \%)$.
A second set of measurements has been made for evaluating the performance of the proposed lamp architecture at a wide range of voltages that can reach a PV system with $12 \mathrm{~V}$ of nominal voltage. Results are shown in Table II.

It can be observed that the LED lamp power varies from $12.98 \mathrm{~W}$ at $12.6 \mathrm{~V}(105.52 \%$ of the nominal power) to $7.37 \mathrm{~W}$ at $11 \mathrm{~V}(59.92 \%$ of the nominal power). This is a good behavior for PV stand-alone systems as the lamp consumption is reduced at low voltage just when the state of charge of the battery is also low, which contributes to a good energy management of the PV system, whilst maintaining a good level of illumination $(676 \mathrm{~lm}$ and $91.72 \mathrm{~lm} / \mathrm{W})$.

The LED lamp efficacy around the nominal voltage $(12.3-12.6 \mathrm{~V})$ is always over $100 \mathrm{~lm} / \mathrm{W}$ and, in the worst

Table II. Performance at the range of voltages in typical solar home systems and $40^{\circ} \mathrm{C}$ of ambient temperature.

\begin{tabular}{|c|c|c|c|c|c|c|c|c|c|}
\hline & $\begin{array}{l}\text { Lamp } \\
\text { voltage } \\
(\mathrm{N})\end{array}$ & $\begin{array}{l}\text { Lamp } \\
\text { current } \\
\text { (A) }\end{array}$ & $\begin{array}{l}\text { Lamp } \\
\text { power } \\
\text { (W) }\end{array}$ & $\begin{array}{c}\text { Illuminance } \\
\qquad(\mathrm{x})\end{array}$ & $\begin{array}{l}\text { Luminance } \\
\qquad(\mathrm{lm})\end{array}$ & $\begin{array}{c}\text { Luminance/ } \\
\text { nominal } \\
\text { luminance }(\%)\end{array}$ & $\begin{array}{c}\text { Efficacy } \\
(\mathrm{m} / \mathrm{W})\end{array}$ & $\begin{array}{c}\text { Efficacy/ } \\
\text { nominal } \\
\text { efficacy }(\%)\end{array}$ & $\begin{array}{c}\text { Duty-cycle } \\
(\%)\end{array}$ \\
\hline Nominal & 12.55 & 0.98 & 12.30 & 145 & 1230 & 100.00 & 100.01 & 100.00 & 100.00 \\
\hline Matrix with 12 LEDs & 11.00 & 0.67 & 7.37 & 80 & 676 & 54.96 & 91.72 & 91.71 & 100.00 \\
\hline \multirow[t]{6}{*}{ on, $\mathrm{R}=2.7 \Omega$} & 11.20 & 0.72 & 8.06 & 86 & 727 & 59.09 & 90.13 & 90.12 & 100.00 \\
\hline & 11.40 & 0.77 & 8.78 & 91 & 773 & 62.81 & 88.01 & 88.00 & 100.00 \\
\hline & 11.60 & 0.82 & 9.51 & 97 & 818 & 66.53 & 86.03 & 86.02 & 100.00 \\
\hline & 11.80 & 0.88 & 10.38 & 102 & 864 & 70.25 & 83.21 & 83.20 & 100.00 \\
\hline & 12.00 & 0.94 & 11.28 & 109 & 920 & 74.79 & 81.56 & 81.55 & 100.00 \\
\hline & 12.20 & 1.03 & 12.57 & 119 & 1011 & 82.23 & 80.49 & 80.48 & 100.00 \\
\hline \multirow{10}{*}{$\begin{array}{l}\text { Matrix with } 16 \text { LEDs } \\
\text { on }\end{array}$} & 12.30 & 0.84 & 10.33 & 127 & 1072 & 87.19 & 103.80 & 103.79 & 100.00 \\
\hline & 12.40 & 0.89 & 11.04 & 134 & 1139 & 92.56 & 103.16 & 103.16 & 100.00 \\
\hline & 12.50 & 0.94 & 11.75 & 142 & 1200 & 97.52 & 102.09 & 102.08 & 100.00 \\
\hline & 12.60 & 1.03 & 12.98 & 151 & 1281 & 104.13 & 98.69 & 98.68 & 100.00 \\
\hline & 12.80 & 0.98 & 12.54 & 137 & 1164 & 94.63 & 92.79 & 92.78 & 88.15 \\
\hline & 13.20 & 0.94 & 12.41 & 126 & 1067 & 86.78 & 86.02 & 86.01 & 73.52 \\
\hline & 13.60 & 0.90 & 12.24 & 134 & 1133 & 92.15 & 92.60 & 92.59 & 62.48 \\
\hline & 14.00 & 0.85 & 11.90 & 123 & 1042 & 84.71 & 87.56 & 87.55 & 52.95 \\
\hline & 14.40 & 0.83 & 11.95 & 113 & 956 & 77.69 & 79.95 & 79.94 & 46.97 \\
\hline & 14.80 & 0.81 & 11.99 & 107 & 910 & 73.97 & 75.89 & 75.89 & 41.76 \\
\hline
\end{tabular}

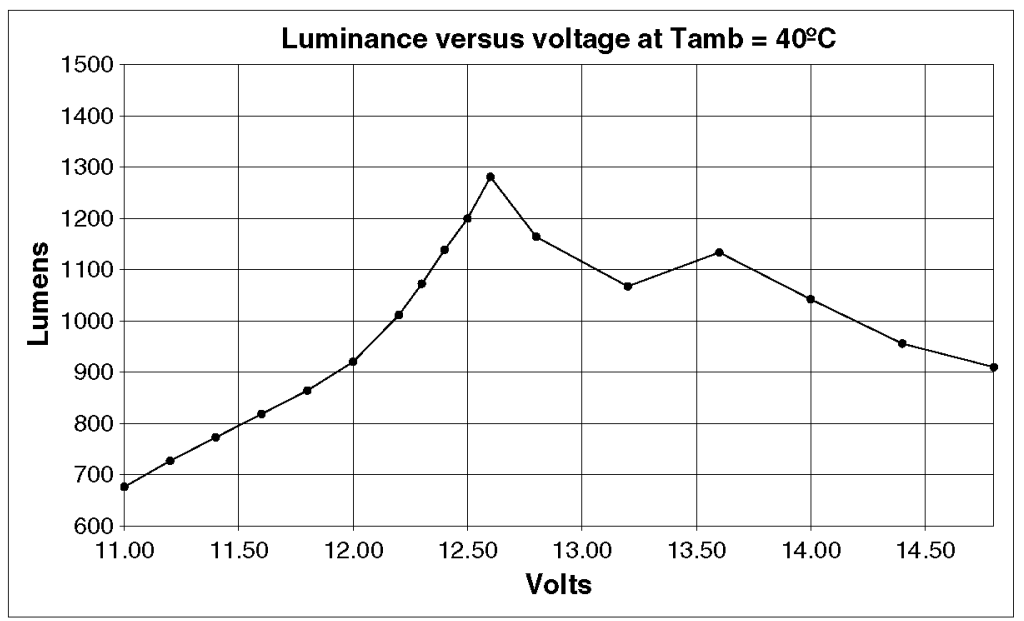

Figure 7. Luminance versus voltage at $40^{\circ} \mathrm{C}$ room temperature. 
case, it is reduced to $75.89 \mathrm{~lm} / \mathrm{W}$. These levels of efficacy mean an increase of performance quality in the current state of the art of PV lighting domestic systems [11,12].

Figure 7 shows the fluctuation in the luminance as a function of supply voltage. This fluctuation ranges between $54.96 \%$ and $104.13 \%$ regarding nominal luminance. Although this fluctuation may seem quite large, the luminance is always greater than $1000 \mathrm{~lm}$ around the nominal voltage. Even at low voltages, just before the charge regulator cuts off the service to protect the battery $(>11.2 \mathrm{~V}$ ), the luminance is over $700 \mathrm{~lm}$, which can be considered sufficient for usual applications.

\section{CONCLUSIONS}

Light-emitting diodes are likely to become the main highly energy-efficient light sources used in all major lighting applications including PV rural electrification. However, in order to achieve this goal it is necessary to understand and assess LED quality-affecting factors and to manage control configuration schemes to optimize their behavior for the quality assurance of solar home systems illumination. It has been shown that reliability is the key quality factor, and this means controlling the operating temperature of LED lamps.

This paper proposes a LED lamp without IDC sources that can be directly connected to the PV system batteries and whose LED driver is based on LED temperature feedback. This architecture allows the LED lamps to be powered directly via a constant voltage power supply, without adding a constant current driver, which makes it very easy to adapt to any solar home systems.

The main conclusions of the evaluation of the proposed LED lamp prototype are the following. The temperature feedback based control maintains the LED matrix always under $65^{\circ} \mathrm{C}$, whereas a constant current control increases up to $80^{\circ} \mathrm{C}$. This means an increment in lifetime expectation of $25 \%$.

The energy efficiency of the proposed control scheme is $15 \%$ higher than that obtained with a constant current control placed on the same lamp.

At the wide range of battery voltages, the lamp efficacy is between 75.89 and $103.80 \mathrm{~lm} / \mathrm{W}$ and the luminosity between 676 and $1281 \mathrm{~lm}$. This large fluctuation is not problematic, because both parameters are kept at high levels within the current state of the art. Moreover, the power consumption decreases significantly as the voltage goes down $(59.92 \%$ of the nominal power at $11 \mathrm{~V}$ supply voltage), resulting in a good energy management system.

\section{REFERENCES}

1. Bergh A, Cradford G, Duggal A, Haitz R. The promise and challenge of solid-state lighting. Physics Today 2001; 4: 42-47. DOI: 10.1063/1.1445547

2. Steigerwald DA, Bhat JC, Collins D, Fletcher RM, Holcomb MO, Ludowise MJ, Martin PS, Rudaz SL. Illumination with solid state lighting technology. IEEE Journal of Selected Topics in Quantum Electronics 2002; 8: 310-320. DOI: 10.1109/2944.999186

3. Zarr R. Extending the life of LED lighting systems. LED Journal 2010; 5: 13-14.

4. Zhou Y, Narendran N. Photovoltaic-powered lightemitting diode lighting systems. Optical Engineering 2005; 44: 1113111-1113116. DOI: $10.1117 /$ 1.2130109

5. Narvarte L, Muñoz J, Lorenzo E. Testing of fluorescent DC lamps for solar home systems. Progress in Photovoltaics: Research and Applications 2001; 9: 475-489. DOI: 10.1002/pip.396

6. Narendran N, Gu Y. Life of LED-based white light sources. IEEE/OSA Journal of Display Technology 2005; l: 167-171. DOI: 10.1109/JDT.2005.852510

7. Loo KH, Lun W, Tan S, Lai Y, Tse C. On driving techniques for LEDs: toward a generalized methodology. IEEE Transactions on Power Electronics 2009; 24 : 2967-2976. DOI: 10.1109/TPEL.2009.2021183

8. Cree. 2011. Cree XLamp Long-Term Lumen Maintenance. http://www.cree.com/ [accessed on 27 January 2011].

9. Van Der Broeck H, Sauerlander G, Wendt M. Power driver topologies and control schemes for LEDs. Proceedings of the 22nd Annual. IEEE Applied Power Electronics Conference and Exposition. 2007; 1319-1325. DOI: 10.1109/APEX.2007.357686

10. Freyssinier JP, Taylor J, Frering D, Rizzo P. Considerations for successful LED applications. Proceedings of China SSL 2009, 6th China International Forum on Solid State Lighting 2009: 206-209.

11. Thermie B UP, EC-DGXVII. Universal technical standard for solar home systems. 1998.995-96.

12. Egido MA, Lorenzo E, Narvarte L. Universal technical standard for solar home systems. Progress in Photovoltaics: Research and Applications 1998; 6: 315-324. DOI: $10.1002 /(\mathrm{SICD}) 1099-159 \mathrm{X}(1998090) 6: 5<315:$ : AID-PIP229 > 3.0.CO;2-E 